\title{
Fiber Based Modeling Strategies of RC Columns
}

\author{
${ }^{1,2}$ Fazil Abdulkadir Caglar iD and ${ }^{1}$ Tuba Tatar ${ }^{\text {iD }}$ \\ ${ }^{1}$ Faculty of Engineering, Department of Civil Engineering Sakarya University, Turkey \\ ${ }^{2}$ Faculty of Engineering, Department of Civil Engineering Bolu Abant Izzet Baysal University, Turkey
}

Received: / Accepted: 16-December-2021 / 28-December-2021

\begin{abstract}
Although experimental studies have proven as the most effective method, its high cost has provoked researchers to seek alternative approaches. The increase in computational power in the $21^{\text {st }}$ century provides the opportunity to numerically model experimental studies with various programs. This study examines the comparison of force-based element and displacement-based element in columns using nonlinear fiber elements. Within the scope of the study, OpenSees program is employed for reinforced concrete (RC) columns selected from the PEER (Structural Performance Database) site. Physical regularization technique is applied to the elements while considering the plastic hinge length of the columns. The aim is to compare the employment of the force-based (FB) element and displacement-based (DB) elements in RC columns in terms of number of elements and integration points, to simulate the global behavior of the columns numerically, and to optimize the parameters that affect the results.
\end{abstract}

Key words: Fiber Elements, Reinforced Concrete, Calibration, Finite Elements, OpenSees

\section{Introduction}

Experimental studies are one of the most effective methods in examining the behavior of structures/structural components. However, their high cost sought researchers to find out new alternatives. While the computational power has increased, numerical investigations are the potential to have information about the behavior of the structural element without performing experimental work. It is, however, necessary to verify that the models made in these programs can give results close to the experimental studies at a sufficient level. Meanwhile, the verification process contains calibration steps as well. If the obtained results via the numerical simulation are matched, the behavior of the building elements can be obtained in a short time frame.

In the experimental tests, it is observed that the nonlinear behavior of the element is accumulated in a certain length along with the height, which can be called the damage zone. In order to have a better understanding of the calibration strategies applied to the models in this study, it is necessary to mention the concept of plastic hinges. Plastic hinges are junction points that carry bending moment up to a certain level and allow rotation in bending moment magnitudes exceeding their capacities. Here, the point that separates the joint from the plastic hinge is that it tolerates some degree of the moment. Many have worked on experiments, and several empirical models have been developed because the plastic hinges have complicated 
interactions between constituent materials and high nonlinearity of materials. These models are shown in Table 1.

Table 1. Empirical plastic hinge length calculation proposed by researchers

\begin{tabular}{|c|c|c|}
\hline The Equations & Reseachers & Definition of the parameters \\
\hline 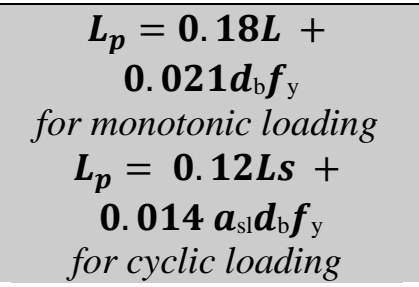 & $\begin{array}{l}\text { Panagiotakos \& } \\
\text { Fardis [1] }\end{array}$ & $\begin{array}{l}\mathrm{L}_{\mathrm{p}} \text { : equivalent plastic hinge length } \\
\mathrm{db} \text { : diameter of longitudinal reinforcement } \\
\mathrm{f}_{\mathrm{y}} \text { : yield strength of longitudinal reinforcement }\end{array}$ \\
\hline$L_{p}=0.8 k_{1} k_{3}\left(\frac{L}{D}\right) c$ & Baker [2] & $\begin{array}{l}k_{1}: \text { equal to } 0.7 \text { for mild steel } \\
\mathrm{k}_{3}: 0.9 \text { for cold-worked steel } \\
\text { c: the neutral axis depth } \\
\text { L: columns length } \\
\text { D: the section depth to assess the response of } \\
\text { reinforced concrete beams }\end{array}$ \\
\hline $\begin{array}{c}L_{p} \\
=0.25 d+0.075 z\end{array}$ & Sawyer [3] & $\begin{array}{l}\mathrm{d} \text { : distance from outer compressive fiber to } \\
\text { centroid of tensile reinforcement } \\
\text { z: spacing of transverse reinforcement }\end{array}$ \\
\hline \begin{aligned} & \multicolumn{1}{c}{$L_{p}$} \\
$= & 0.5 d[1 \\
+ & (0.4 / \sqrt{d})]\left(\frac{z}{d}\right)\end{aligned}$ & Corley [4] & $\begin{array}{l}\mathrm{d} \text { : distance from outer compressive fiber to } \\
\text { centroid of tensile reinforcement } \\
\text { z: spacing of transverse reinforcement }\end{array}$ \\
\hline$L_{p}=0.5 d+0.05 z$ & Mattock [5] & $\begin{array}{l}\mathrm{d} \text { : distance from outer compressive fiber to } \\
\text { centroid of tensile reinforcement } \\
\text { z: spacing of transverse reinforcement }\end{array}$ \\
\hline $\begin{array}{c}\boldsymbol{L}_{\boldsymbol{p}}=0.08 d+ \\
\quad 0.022 d_{\mathrm{b}} f_{\mathrm{y}}\end{array}$ & $\begin{array}{l}\text { T. Paulay, M.J.N. } \\
\text { Priestley [6] }\end{array}$ & $\begin{array}{l}\mathrm{f}_{\mathrm{y}} \text { : yield strength of longitudinal reinforcement } \\
\mathrm{d} \text { : length from section of maximum moment to } \\
\text { the point of inflection } \\
\mathrm{d}_{\mathrm{b}} \text { : bar diameter for the longitudinal } \\
\text { reinforcement }\end{array}$ \\
\hline $\begin{aligned} & L_{p} \\
= & 0.5(1.06 d \\
+ & 0.13 \rho V) d\end{aligned}$ & Naaman et al. [7] & $\begin{array}{l}\rho: \text { reinforcement ratios } \\
\mathrm{d} \text { : distance from outer compressive fiber to } \\
\text { centroid of tensile reinforcement } \\
V: \text { shear force }\end{array}$ \\
\hline$=0.05 L+\frac{L_{p}}{0.1 f_{y} d_{b}}$ & Berry et al. [8] & $\begin{array}{l}f_{c} \text { : concrete compressive strength } \\
f_{y} \text { : yield strength of longitudinal reinforcement } \\
d_{b} \text { : diameter of column longitudinal reinforcing } \\
\text { steel } \\
\text { L: column length from point of maximum } \\
\text { moment at column base to point of zero moment } \\
\text { at }\end{array}$ \\
\hline$L_{p}=h$ & Sheikh et al. [9] & $\begin{array}{l}\mathrm{L}_{\mathrm{p}} \text { : Equivalent plastic hinge length } \\
\mathrm{h} \text { : Total column depth }\end{array}$ \\
\hline$L_{p}=(0.3+0.18 \rho) d$ & Tariq et al. [10] & $\begin{array}{l}\rho \text { : reinforcement ratios } \\
\mathrm{d} \text { : distance from tensile longitudinal } \\
\text { reinforcement to the extreme compression fiber }\end{array}$ \\
\hline
\end{tabular}


Distributed inelasticity elements are employed in earthquake engineering applications such as research or professional engineering purposes. Concentrated plasticity and distributed plasticity are the two general approaches used in the numerical analysis of frame structures. The concentrated plasticity assumes that the nonlinear behaviour is in a limited zone, mainly in a null or zero-length element, and the remaining part of the element behaves linearly. Although concentrated plasticity is an approach that has been used and accepted for many years, the distributed plasticity approach has developed considerably with the advancement of computer power. With distributed inelasticity models, the inelasticity is dispersed at each section throughout the member. The inelasticity of the frame is controlled by each integration point. This approach shows a profound closeness to the experimental results [11]. The distributed plasticity is also explored in two main finite element formulations: force-based and displacement-based formulations within the fiber element concept (in addition, OpenSees offer an element mixing force-based element and concentrated plasticity as a third option, named "beamwithhinge element"). The fiber element in the distributed plasticity is a method based on uniaxial stress-strain curves of the material, discretizing the sections into many fiber elements at the sectional level and integration points (IP) along the element length. The approach is very popular in earthquake engineering and the open-source software, OpenSees, provides a very wide, accessible, and independent platform for the users. Figure 1 illustrates the comparison of the plasticity types.
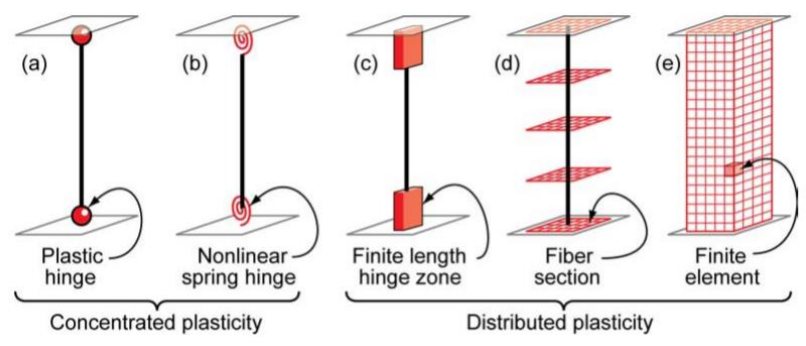

Figure 1. Various of the type of plasticity in an element [12]

This study examines the comparison of force-based elements and displacement-based elements in columns using nonlinear fiber elements. Within the scope of the study, the OpenSees program is employed for columns selected from the PEER (Structural Performance Database) site. The aim is to compare the employment of the FB element and DB elements in RC columns in terms of the number of elements and integration points, to simulate the global behaviour of the columns numerically, and to optimize the parameters that affect the results.

\section{Selection of Columns and Their Properties}

The PEER Database is utilized while selecting the experimental test in this study [13]. During the selection process, the failure type of the column is the key parameter and the columns with flexural failure are selected. Table 2 shows the column selection window of the PEER Database summarizes the material and geometrical properties of the selected columns for the paper. The material and geometrical properties of the columns are discussed in detail below: 


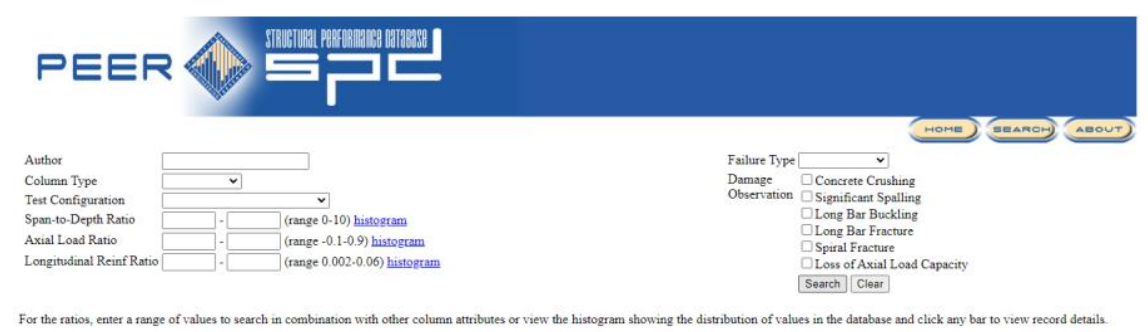

Figure 2: The selection window of the PEER Database [13]

\subsection{Bayrak_AS-6HT Column}

(Bayrak,1996), presents the results of an ongoing research program aimed at examining concrete wrapping with lateral reinforcement. The present study is concerned with the experimental behaviour of high strength concrete (HSC) and ultra-high strength concrete (UHSC) column behaviour. In experimental program, specimen consisted of a $0.305 \mathrm{~m} \mathrm{x} 0.305$ $\mathrm{m} \times 1.473 \mathrm{~m}$ column and they applied $4360 \mathrm{kN}$ axial load [14].

\subsection{Matamoros_C10-05S Column}

(Matamoros,1999), was carried out to investigate the behaviour of columns made with highstrength concrete subjected to shear reversals. The main variables of the experimental study were axial load and concrete strength. Column dimensions and the amount of transverse reinforcement did not vary between specimens. The dimensions of the samples are $0.203 \mathrm{~m} \mathrm{x}$ $0.203 \mathrm{~m} \times 0.610 \mathrm{~m}$. The axial load we used in our study is $142 \mathrm{kN} \mathrm{[15].}$

\subsection{Ohno_L2 Column}

(Ohno,1984), have proposed that the energy absorption capacity of structures is well-suited index for seismic safety. They investigate the energy absorption capacity of structures quantitatively. Five reinforced concrete columns were tested under four types of repeated loading. The dimensions of the samples are $0.4 \mathrm{~m} \times 0.4 \mathrm{~m} \times 1.6 \mathrm{~m}$. The axial load we used in our study is $127 \mathrm{kN}[16]$.

\subsection{Saatcioglu_BG8 Column}

(Saatcioglu,1999) Experimental research was conducted to investigate structural performance of reinforced concrete columns confined with welded grids. Ten column specimens were designed, constructed and tested. The dimensions of the samples are $0.35 \mathrm{~m} \times 0.35 \mathrm{~m} \times 1.645$ $\mathrm{m}$. The axial load we used in our study is $961 \mathrm{kN}$ [17].

\subsection{Saatcioglu_U7 Column}

(Saatcioglu,1989) In this study, the effect of reinforced concrete columns on seismic loading was investigated. Full-scale columns were tested under slowly applied lateral load reversals. Both unidirectional and bidirectional loadings were included. The dimensions of the samples are $0.35 \mathrm{~m} \times 0.35 \mathrm{~m} \times 1 \mathrm{~m}$. The axial load we used in our study is $600 \mathrm{kN} \mathrm{[18].}$

\subsection{Tanaka No. 5 Column}

(Tanaka,1990) Basically, in his thesis, he studied the effect of lateral limiting reinforcement on 
the ductile behaviour of reinforced concrete columns. The dimensions of the samples are 0.55 $\mathrm{m} \times 0.55 \mathrm{~m} \times 1.65 \mathrm{~m}$. The axial load we used in our study is $968 \mathrm{kN}$ [19].

\subsection{Rodrigues Column}

Rodrigues in his thesis, focuses on the assessment of the structural response of RC columns under bidirectional horizontal loads in three main streamlines. The dimensions of the samples are $0.2 \mathrm{~m} \times 0.4 \mathrm{~m} \times 1.7 \mathrm{~m}$. The axial load we used in our study is $170 \mathrm{kN}$ [20].

Table 2. Material and sectional properties of the selected columns

\begin{tabular}{|cccccccc} 
Specimen & $\begin{array}{c}\text { Concrete } \\
\text { Strength } \\
\text { (MPa) }\end{array}$ & $\begin{array}{c}\text { Stirrup } \\
\text { Yield } \\
\text { Stress } \\
(\mathbf{M P a})\end{array}$ & $\begin{array}{c}\text { Stirrup } \\
\text { Strength } \\
(\mathbf{M P a})\end{array}$ & $\begin{array}{c}\text { Longitudinal } \\
\text { Rebar Yield } \\
\text { Stress (MPa) }\end{array}$ & $\begin{array}{c}\text { Longitudinal } \\
\text { Rebar Bar } \\
\text { Ratio }(\%)\end{array}$ & $\begin{array}{c}\text { Axial } \\
\text { Load } \\
(\mathbf{k N})\end{array}$ \\
\hline Bayrak_AS-6HT & 101.9 & 463 & 648 & 454 & 2.58 & 4360 \\
\hline Matamoros_C10-05S & 69.6 & 406.8 & 639.5 & 586.1 & 1.93 & 142 \\
Ohno_L2 & 24.8 & 325 & 0 & 362 & 1.42 & 127 \\
\hline Saatcioglu_BG8 & 34 & 580 & 720 & 455.6 & 2.93 & 961 \\
Saatcioglu_U7 & 39 & 425 & 0 & 437 & 3.21 & 600 \\
Tanaka No.5 & 32 & 325 & 429 & 511 & 1.25 & 968 \\
Rodrigues & 48.4 & 4 & 500 & 432 & 0.85 & 170 \\
\hline
\end{tabular}

\section{Modeling on OpenSees}

The given material properties by the experimental results for each column are used in the numerical models. The concrete elements are modelled using Concrete 04 for confined concrete and Concrete 01 for unconfined concrete, representing the concrete cover.

Figure 3 displays the stress-strain relation for the concrete material. Reinforcing steel is utilized from the software library for the longitudinal reinforcing bar. The buckling of reinforcing bars is considered, and the unsupported length for local buckling is computed for each column (S). Calabrese et al. emphasized the numerical issues on the distributed plasticity and enlightened physical regularization techniques to eliminate them for the objective and non-objective responses [21]. Those physical regularization techniques are employed on the numerical models. For FB elements, the number of IP is selected using an aspect in which the plastic hinge length over the height of the column provides a good approximation. The plastic hinge length is assumed being equal to the greatest section size of the column. [9] And for DB elements, the same perspective is implied to the height of the first element (employed two elements for all cases with 2 IP in each case). 


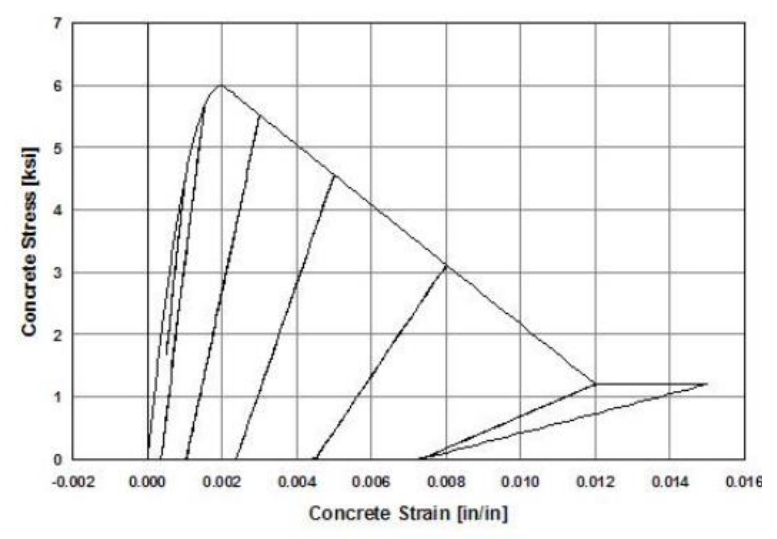

(a). Concrete01 Stress - Strain Curve

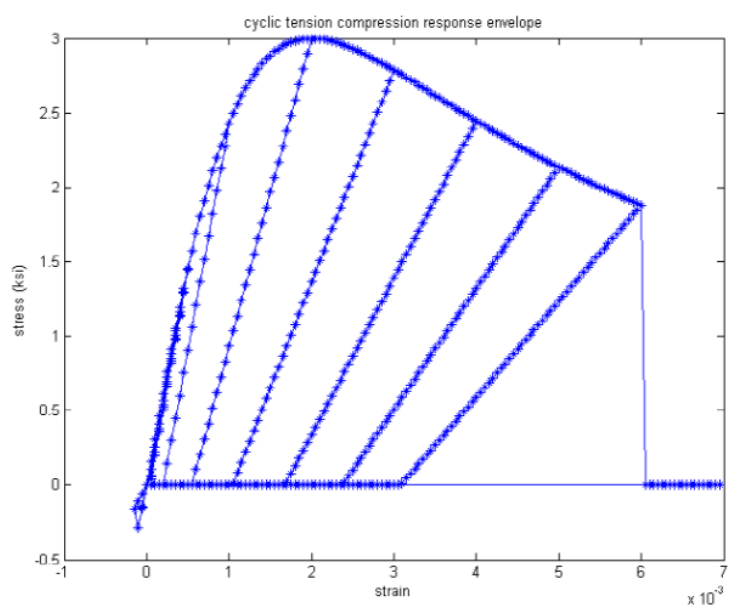

(b). Concrete04 Stress - Strain Curve

Figure 3: The selected models for confined and unconfined concrete in the models [22]

\section{Results}

Figure 4 compares the results obtained for each selected column using different fiber element types. In general, both element types provide good agreement with the experimental results. The displacement-based element provides a stiffer response, and the convergence problem can be observed, especially among the models with a high axial load level. The force-based element may have some difficulties regarding the convergence problem, and the divergence may occur at an early stage of the analysis; however, there is a greater agreement in terms of the maximum base shear between the experimental results. Pinching phenomena were able to capture through the numerical models in both element types because buckling is considered using reinforcing steel element for steel, and local buckling length is computed. The hardening and softening behaviour of the columns (which is related to the axial load level) can be simulated well. The Bayrak AS-6HT column shows great agreements in both element types, while the FB elements show greater match specifically along with the softening range. The Matamoros column with the FB element is able to simulate the maximum and elastic zone better. Meanwhile, the model with the DB element shows some dispersions through the softening zone. The pinching behaviour is captured better on the model with the FB element. The Ohno column model with the FB element displays a very good agreement on the softening range and is able to capture the ultimate displacement. Both models of the Saatcioglu BG8 column are not able to capture the pinching, but overall, they do have good agreement with the two models. The models for the Saatcioglu U7 column captures pinching very well. However, the model with the FB element shows lower and the model with the DB element higher global response than the experimental results. For the Tanaka column, the model with the FB element illustrates a better agreement regarding maximum response, softening zone, and pinching. The results are compared in detail in

Table 3 . 


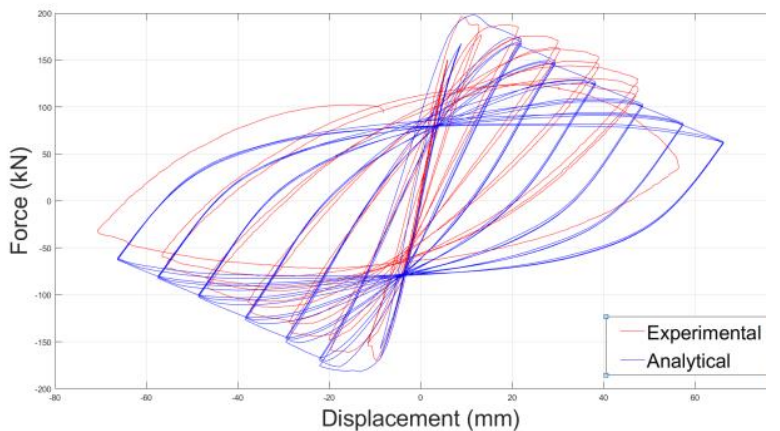

a. Bayrak AS-6HT FB

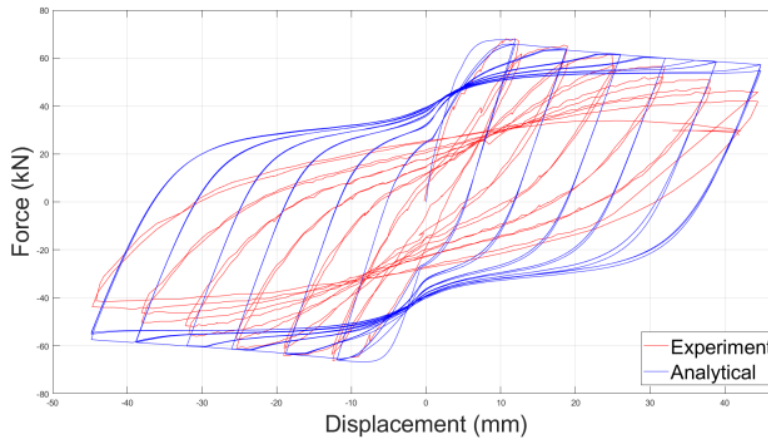

c. Matamoros FB

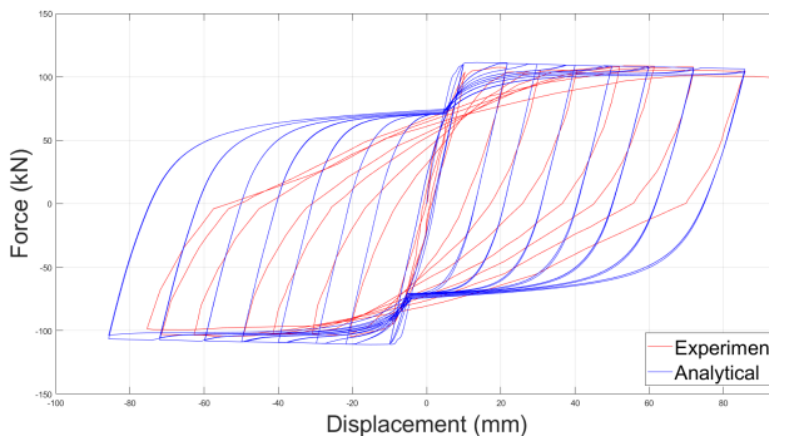

e. Ohno FB

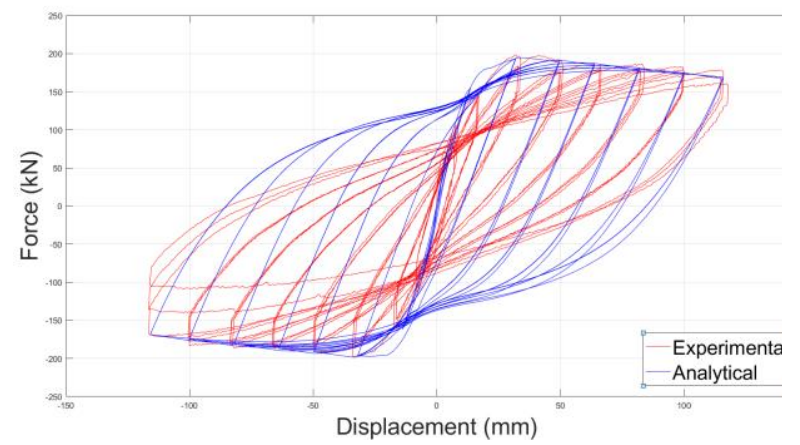

g. Saatcioglu BG8 FB

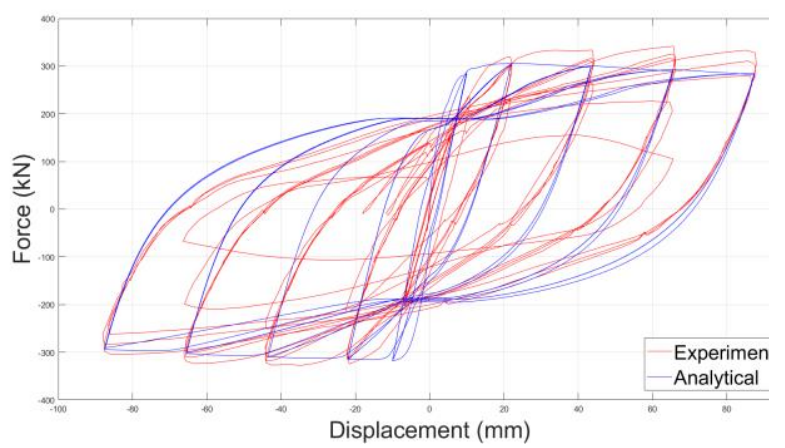

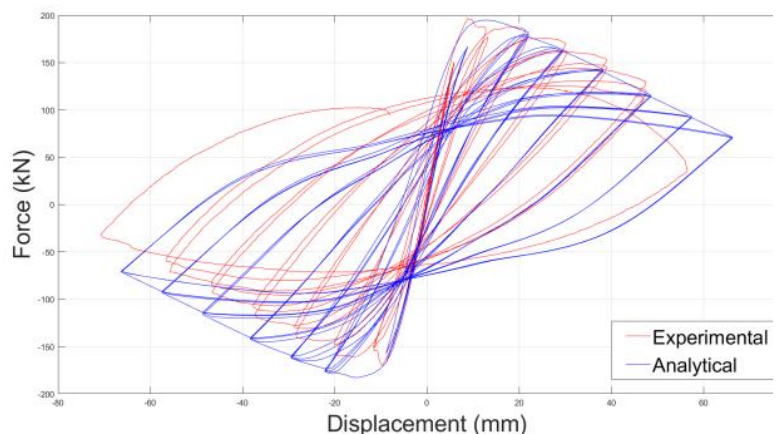

b. Bayrak AS-6HT DB

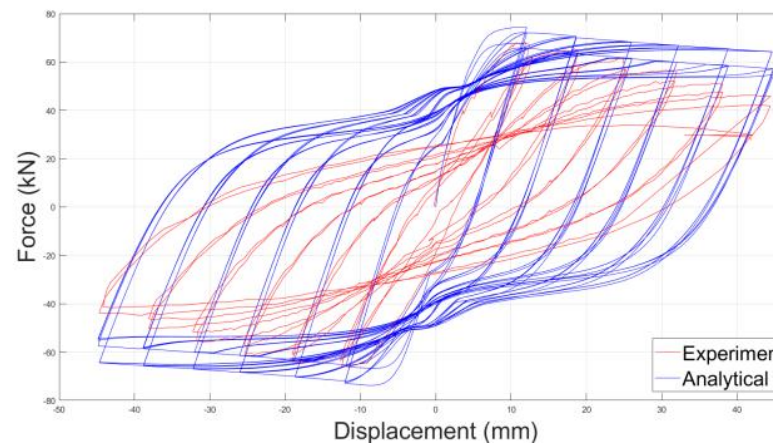

d. Matamoros DB

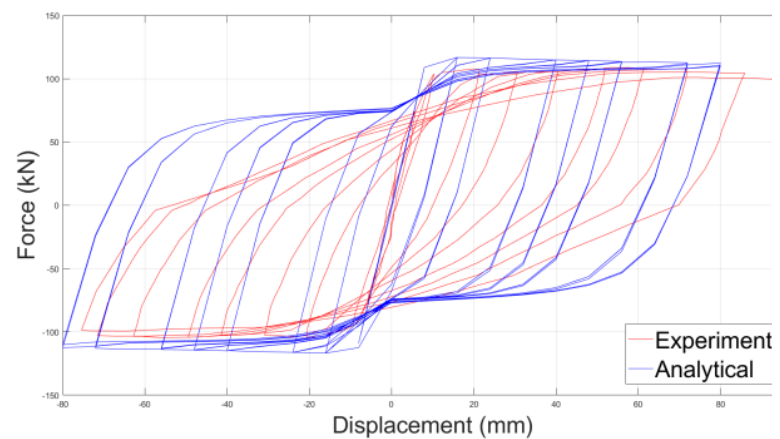

f. Ohno DB

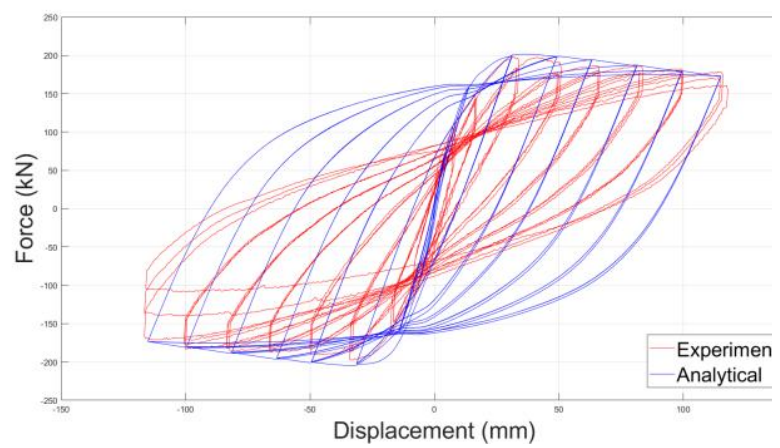

h. Saatcioglu BG8 DB

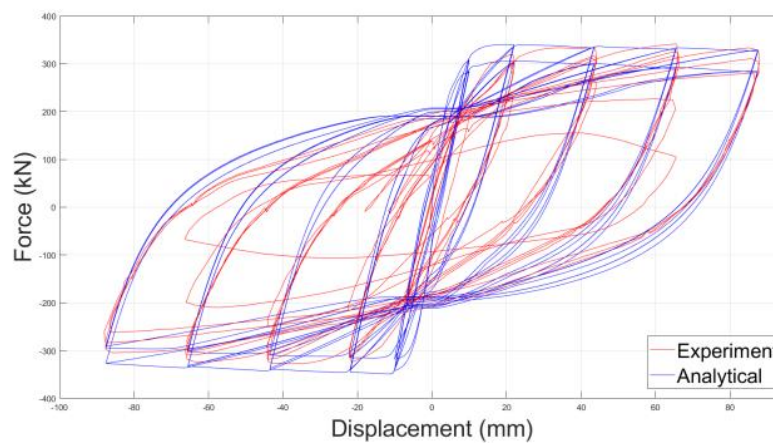


i. Saatcioglu U7 FB

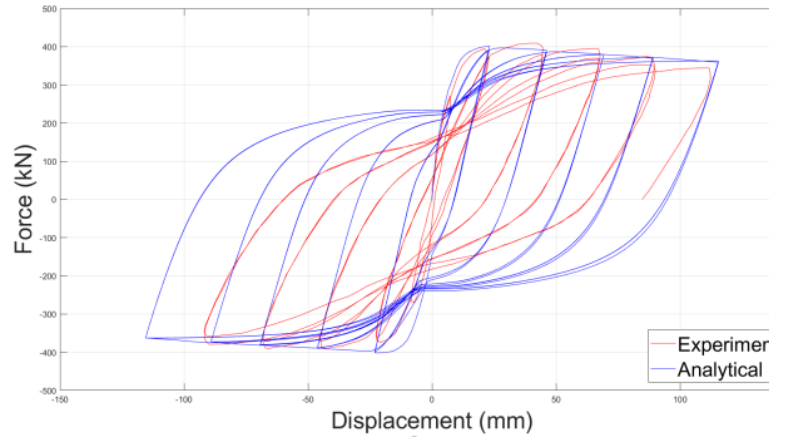

k. Tanaka FB

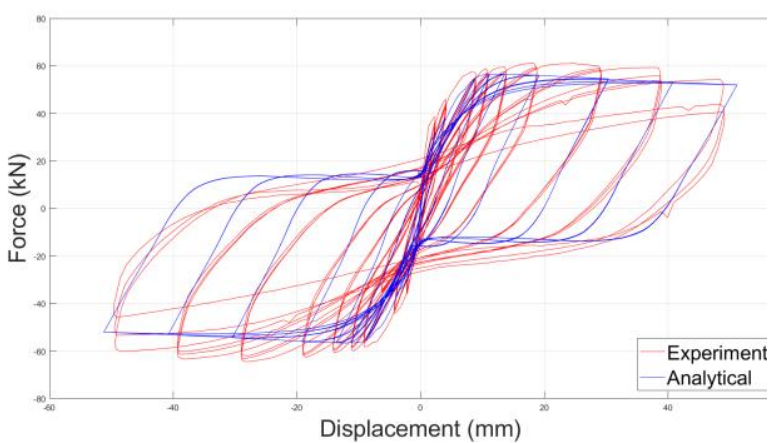

m. Rodrigues FB j. Saatcioglu U7 DB

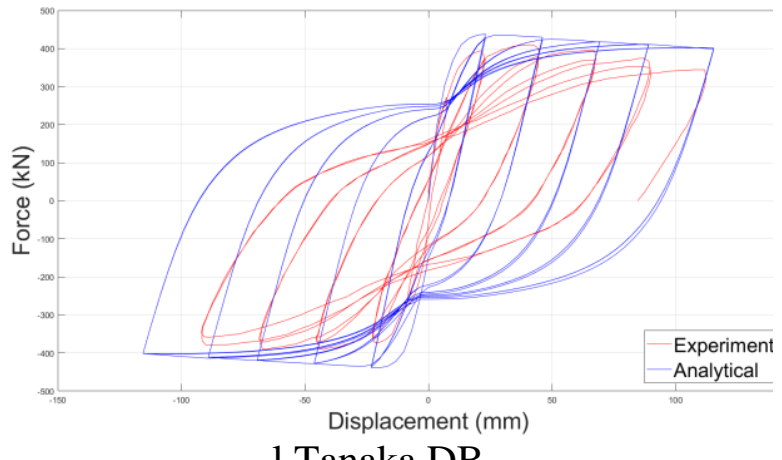

1.Tanaka DB

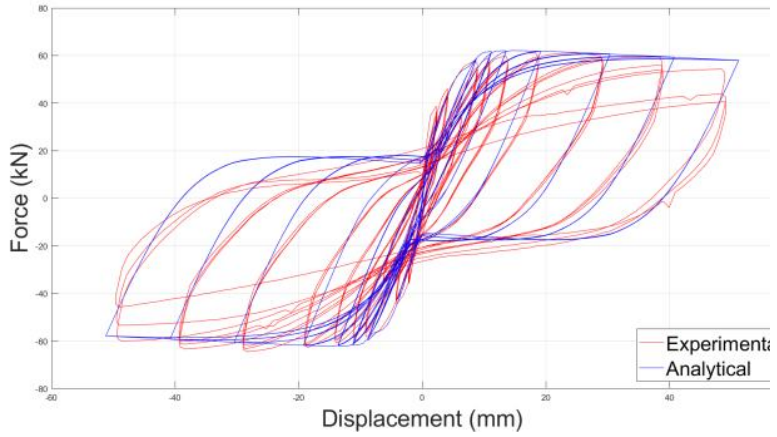

n. Rodrigues DB

Figure 4: (a-n) Comparison of the global responses for each column using FB and DB elements

\section{Summary and Conclusion}

This paper simulates seven columns available in the literature using numerical models via the OpenSees software and figuring out the parameters that influence the global responses of the columns. Two types of the element, FB and DB elements, are utilized, and physical regularization techniques are employed while selecting IP numbers and the number of elements.

Table 3 provides the details in results obtained from the numerical models and compares them with the experimental results. In the global sense, very good agreements are achieved using both element types. However, the DB elements provided stiffer responses before the maximum point. The FB element, however, showed slightly better agreements, specifically capturing the softening behaviour. The results of the column of Bayrak illustrate a good agreement in FB and DB models. Both could capture the initial stiffness, the maximum response, pinching, and softening slope. The maximum response obtained at the test is $196.55 \mathrm{kN}$, and the FB and DB numerical models achieved $198.49 \mathrm{kN}(+0.99 \%$ error) and $194.95 \mathrm{kN}(-0.81 \%$ error), respectively. The experimental result of the Matamoros column is $68.05 \mathrm{kN}$, and the results gathered from the FB element models are $67.84 \mathrm{kN}$ (-0.3\% error), and from the DB element model is $74.331 \mathrm{kN}$ ( $+9.22 \%$ error). The Ohno models show agreeable results as well. In the FB model, global behaviour is captured slightly better because the agreement with the softening behaviour and pinching are more suitable. The maximum response obtained at the test is 108.7 $\mathrm{kN}$, and the FB and DB numerical models achieved $11.35 \mathrm{kN}(+0.99 \%$ error) and $116.787 \mathrm{kN}$ $(-0.81 \%$ error), respectively. The results from Saatcioglu BG8 models from experimental, FB, and DB models are $198.48 \mathrm{kN}, 198.28 \mathrm{kN}$ (0.1\% error), and $205.009 \mathrm{kN}$ (3.28\% error), respectively. The global responses match in good agreement with the experimental result. The maximum response of the Saatcioglu U7 column obtained at the test is $341.80 \mathrm{kN}$, and the FB and DB numerical models achieved $317.89 \mathrm{kN}(-6.99 \%$ error $)$ and $348.672 \mathrm{kN}(+2.01 \%$ error), 
respectively. The results of the column of Tanaka illustrate a fair agreement in FB and DB models. Both could capture the initial stiffness, the maximum response, pinching, and softening slope. The maximum response obtained at the test is $409.20 \mathrm{kN}$, and the FB and DB numerical models achieved $401.58 \mathrm{kN}(-1.86 \%$ error) and $438.962 \mathrm{kN}(+7.27 \%$ error), respectively. The experimental response of the Rodrigues column is $68.4 \mathrm{kN}$. The obtained results from the FB and DB models are $66.67 \mathrm{kN}(-2.53 \%$ error) and $72.56 \mathrm{kN}$ (+ $6.08 \%$ error), respectively. In these models, pinching has been captured well.

Since the DB element demonstrates stiffer and approximate solutions, initial stiffness in all the columns shows stiffer response, and the results with the FB element display smaller errors. The FB element provides an exact solution for linear and nonlinear elements. Exceptionally, the Saatcioglu_U7 column result with the DB element reveals better agreement. One reason could be standing as a short column, in which the triple size of the section is the height of the column. Meanwhile, assuming the plastic hinge length as the greater size of the section provides a very satisfying response in the models in this study. It could be concluded that the physical regularization techniques are quite effective in reaching out the global match between experimental and numerical results considering the limited number of IPs and elements are employed in the models.

Table 3. Comparison of Experimental and Analytical Results

\begin{tabular}{|c|c|c|c|c|c|c|c|c|c|c|}
\hline \multirow[b]{2}{*}{ Specimen } & \multicolumn{6}{|c|}{ Experimental Tests } & \multicolumn{2}{|c|}{$\begin{array}{c}\text { Results using FB } \\
\text { Elements }\end{array}$} & \multicolumn{2}{|c|}{$\begin{array}{c}\text { Results using DB } \\
\text { Elements }\end{array}$} \\
\hline & $\begin{array}{l}\text { Width } \\
\text { (m) }\end{array}$ & $\begin{array}{l}\text { Depth } \\
\text { (m) }\end{array}$ & $\begin{array}{l}\text { Length } \\
\text { (m) }\end{array}$ & $\begin{array}{c}\text { Axial } \\
\text { Load } \\
\text { Ratio } \\
(\%)\end{array}$ & $\begin{array}{c}\text { S Hoop } \\
\text { Spacing } \\
(\mathrm{mm})\end{array}$ & $\begin{array}{c}\text { Maximum } \\
\text { Base Shear } \\
(\mathrm{kN})\end{array}$ & $\begin{array}{c}\text { Number of } \\
\text { Integration } \\
\text { Points FB }\end{array}$ & $\begin{array}{c}\text { Maximum } \\
\text { Base Shear } \\
\quad(k N)\end{array}$ & $\begin{array}{l}\text { Length } \\
\text { of the } \\
\text { first } \\
\text { element } \\
\text { (m) }\end{array}$ & $\begin{array}{c}\text { Maximum } \\
\text { Base Shear } \\
(\mathrm{kN})\end{array}$ \\
\hline Bayrak_AS-6HT & 0.305 & 0.305 & 1.842 & 0.46 & 76 & 196.55 & $6.03 \approx 6$ & 198.49 & 0.305 & 194.952 \\
\hline $\begin{array}{l}\text { Matamoros_C10- } \\
\text { 05S }\end{array}$ & 0.203 & 0.203 & 0.61 & 0.05 & 76.2 & 68.05 & $3.00 \approx 3$ & 67.84 & 0.203 & 74.331 \\
\hline Ohno_L2 & 0.4 & 0.4 & 1.6 & $0 .($ & 100 & 1 & $4.00 \approx 4$ & 111 & 0.4 & 116.787 \\
\hline Saatcioglu_BG8 & 0.35 & 0.35 & 1.645 & 0 & 76 & & 4.70 & 198.28 & 0.35 & 205.009 \\
\hline Saatcioglu_U7 & 0.35 & 0.35 & 1.00 & 0.12 & 65 & 341.80 & $2.85 \approx 3$ & 317.89 & 0.35 & 348.672 \\
\hline $\begin{array}{l}\text { Tanaka and Park } \\
\text { No.5 }\end{array}$ & 0.55 & 0.55 & 1.65 & 0.1 & 110 & 409.20 & $3 \approx 3$ & 401.58 & 0.55 & 438.962 \\
\hline Rodrigues & 0.2 & 0.4 & 1.70 & 0.04 & 60 & 68.4 & $4.25 \approx 4$ & 67.77 & 0.4 & 73.79 \\
\hline
\end{tabular}

\section{Author Contribution}

T.T. and A.F.C designed the concept of the study. A.F.C. performed the numerical simulation. T.T. and A.F.C. wrote the manuscript.

\section{References}

[1] T. B. , Panagiotakos and M. N., Fardis. "Deformations of Reinforced concrete members at yielding and ultimate.” ACI Structural Journal, vol. 98, no. 2, pp. 135-148, 2001.

[2] Baker, Arthur Lempriere Lancey. The ultimate load theory applied to the design of reinforced \& prestressed concrete frame, London, Concrete Publications Ltd., 1956.

[3] Sawyer, Herbert A. 'Design of concrete frames for two failure stages.' Special Publication 12 pp. 405-437, 1965. 
[4] W. G., Corley. "Rotational capacity of reinforced concrete beams." Journal of the Structural Division, vol. 92, no. 5, pp. 121-146, 1966.

[5] A. H., Mattock. "Discussion of Rotation Capacity of Reinforced Concrete Beams." Journal of the Structural Division, vol. 93, no. 2, pp. 519-522, 1967.

[6] P. Thomas and P. MJ. Nigel. Seismic Design of Reinforced Concrete and Masonry Buildings, Wiley Interscience Publication, New York, 1992.

[7] Naaman, A. E., Paramasivam, P., Balazs, G., Bayasi, Z. M., Eibl, J., Erdelyi, L. Lohrmann, G., "Reinforced and Prestressed Concrete Using HPFRCC Matrices.” High Performance Fiber Reinforced Cement Composites 2, pp. 291-347, 1996.

[8] M. P. Berry and M. O. Eberhard. Performance Modeling Strategies for Modern Reinforced Concrete Bridge Columns, Seattle, 2007.

[9] S.A., Sheikh; D.V., Shah and S.S., Khoury. "Confinement of high strength concrete columns.” ACI Structural Journal, vol. 91, no. 1, pp.100-111(1994).

[10] H. Tariq, E. A. Jampole and M. J. Bandelt. "Fiber-hinge modeling of engineered cementitious composite flexural members under large deformations." Engineering Structures, vol. 182, pp. 62-78, 2019.

[11] O.,Takahashi; Y., Hirona and O. D. A., Minoru. "Research on the Development of the Semi-Rigid Column Base of Reinforced Concrete: Experimental and Analytical Study on the Column Base with Cross Section Reduced Portion." Academic Platform Journal of Natural Hazards and Disaster Management, vol. 1, no. 1, pp. 1-12, 2020.

[12] G. G., Deierlein; A. M., Reinhorn and M. R. Willford. Nonlinear Structural Analysis For Seismic Design 2010.

[13] «PEER Structural Performance Database,» 2003. [Online]. Available: https://nisee.berkeley.edu/spd/index.html [Dec. 20, 2021]

[14] O., Bayrak and S. Sheikh. "Confinement Steel Requirements For High Strength Concrete Columns.” Elsevier Science, 1996.

[15] A. B. Matamoros. Study of Drift Limits For High-Strength Concrete Columns,Urbana,Illinois 1999.

[16] T., Ohno and N., Takashi. "An Experimental Study on Energy Absorption Capacity of Columns in Reinforced Concrete Structures.” Structural Engineering, October 1984.

[17] M. Saatcioglu, and Mongi Grira. "Confinement of Reinforced Concrete Columns With Welded Reinforcement Grids.” ACI Structural Journal, February 1999.

[18] M. Saatcioglu and G., Ozcebe. "Response of Reinforced Concrete Columns to Simulated Seismic Loading.” ACI Structural Journal, February 1989. 
[19] H. F. P., Rodrigues."Biaxial seismic behaviour of reinforced concrete columns." (Doctoral dissertation), University of Aveiro (2012)

[20] J. Tanaka. Effect of Lateral Confining Reinforcement on the Ductile Behavior of Reinforcement Concrete Columns, 1990.

[21] A., Calabrese; J. P., Almeida and R., Pinho.”Numerical Issues in Distributed Inelasticity Modeling of RC Frame Elements for Seismic Analysis" Journal of Earthquake Engineering, 24 Mar 2010.

[22] «The Open System for Earthquake Engineering Simulation,» 2006. [Online]. Available: https://opensees.berkeley.edu/. 